\title{
Memecik Zeytin Çeliklerinin Köklenmesi Üzerine Etilenin Etkisi
}

\author{
Murat KARALTII ${ }^{1}$, Zeynel DALKILIÇ ${ }^{* 1}$ \\ ${ }^{1}$ Aydın Adnan Menderes Üniversitesi Ziraat Fakültesi Bahçe Bitkileri Bölümü Güney Yerleşke 09100 AYDIN
}

Öz: Bu çalışmada, Memecik zeytin çeliklerinin köklenmesi üzerine etilenin etkisinin belirlenmesi amaçlanmıştır. Çalışmada 10 farklı bitki büyüme düzenleyici madde kombinasyonu uygulamasında her uygulamada 3 tekerrür, her tekerrürde 30'ar adet olmak üzere toplam 900 adet zeytin yarı odun çeliği kullanılmıştır. Çalışma sonucunda en yüksek köklenme oranı \%44.4 ile 0 etilen+6000 ppm IBA uygulamasından elde edilirken, bunu \%42.2 ile 0 etilen+8000 ppm IBA uygulaması izlemiştir. En düşük köklenme oranı \%2.2 ile 0 etilen+0 ppm IBA (kontrol) ve 150 etilen+4000 ppm IBA (dikimden 10 gün sonra) uygulamalarında gözlenmiştir. Çeliklerin dikimden itibaren farklı günlerde yapılan bitki büyümeyi düzenleyici maddeleri uygulamalarında en yüksek kallus oranı (\% 44.7) 150 etilen+4000 ppm IBA (20.gün)'da, en fazla kök sayısı (13.3 adet) 0 etilen+6000 ppm IBA'da, en fazla kök uzunluğu $(7.0 \mathrm{~cm}) 50$ etilen+4000 ppm IBA (10.gün)'da ve en fazla kök çapı $(3.0 \mathrm{~mm})$ 150 etilen+4000 ppm IBA (10.gün)'da elde edilmiştir. Sürgün uzunluğu, çapı ve sayısı bakımından uygulamalar arasındaki farkııık önemli bulunmamıştır. Artan etilen dozları Memecik yarı odun çeliklerinin köklenmesini azalttı̆̆ı için 50 ppm'den daha düşük etilen dozlarının denenmesi tavsiye edilmektedir.

Anahtar Kelimeler: Olea europaea, yarı odun çeliği, köklendirme, bitki büyüme düzenleyici maddeleri

Effect of Ethylene on Rooting of Memecik Olive Cuttings Abstract: In this study, it was aimed to determine the effect of ethylene on the rooting of Memecik olive semi-hardwood cuttings. In the
study, 10 different plant growth regulator combinations with three replicates, 30 cuttings in each replication in total of 900 olive cuttings
were used. As a result of this study, while the highest rooting ratio of $44.4 \%$ was obtained from 0 ethylene+6000 ppm IBA application, this
was followed by 0 ethylene +8000 ppm IBA application $44.2 \%$. The lowest rooting ratio of $2.2 \%$ was observed in 0 ethylene+0 ppm IBA
(control) and 150 ethylene +4000 ppm IBA (IBA after 10 days of first application) applications. The highest callus ratio was $44.7 \%$ in 150
ethylene +4000 ppm IBA $\left(20^{\text {th }}\right.$ day), the highest root number was 13.3 in 0 ethylene+6000 ppm IBA, the longest root length was $7.0 \mathrm{~cm}$ in 50
ethylene +4000 ppm IBA (10 $\left(10^{\text {th }}\right.$ day), and the thickest root diameter was $3.0 \mathrm{~mm}$ in 150 ethylene +4000 ppm IBA (10 day). Since increasing
ethylene doses reduced rooting of semi-hardwood cuttings in Memecik cultivar, it is recommended that lower than 50 ppm ethylene doses
would be applied.

Keywords: Olea europaea, semi-hardwood cuttings, rooting, plant growth regulators

\section{GiRiş}

Zeytin Olea europaea $(2 n=2 x=46$, Oleaceae) her mevsim yeşil, genetik yapısı itibariyle periyodisite gösteren, çok yıllık Akdeniz bitki türüdür. Türkiye'de zeytin ağacı asırlardır subtropik iklime sahip yerlerde yetiştirilmektedir. Zeytinin anavatanı, Hatay, Kahramanmaraş ve Mardin illerinin bulunduğu Güneydoğu Anadolu Bölgesi'ni de içine alan Yukarı Mezopotamya ve Güney Ön Asya'dır (Mendilcioğlu, 1999). 2017 yılı itibariyle dünya dane zeytin üretiminde öne çıkan ülkeler İspanya, Yunanistan, İtalya, Türkiye, Fas, Suriye, Tunus, Cezayir, Mısır ve Portekiz'dir (Anonim, 2019). Türkiye yaklaşık 1.7 milyon tonluk üretim hacmiyle dünyada 4. sırada yer almaktadır. Türkiye'deki zeytin üretiminin \%76.0'sı Ege, \%14.0'ü Akdeniz, \%5.7'si Marmara, \%4.0'ü Güneydoğu ve $\% 0.03$ 'ü Karadeniz bölgelerinde yapılmaktadır Türkiye'de toplam ağaç varlığı bakımından en fazla (\%45.5) yetiştiriciliği yapılan çeşit Memecik'tir (Mendilcioğlu, 1999). 2018 yılında ülkemizde en fazla zeytin ağaç varlığı ve üretimi Aydın ilinde gerçekleşmiştir (Anonim, 2018).

Zeytinin en önemli çoğaltma yöntemi olarak yapraklı çeliklerin köklendirilmesi kabul edilse de ülkelerin bazı önemli çeşitlerinin köklenme oranlarının düşük olduğu bilinmektedir (Mendilcioğlu, 1999; Çelik ve Özkaya, 1999; Fabbri ve ark., 2004). Örneğin köklenme oranı Sevillano'da \%20-30 gibi düşükten Manzanillo, Nevadillo ve Picual'da \%95-98 gibi yüksek rakamlara çıkabilmektedir (Ferguson ve ark., 1994). Türkiye'de Domat çeşidi başta olmak üzere, Çilli ve Memecik gibi önemli çeşitler köklenme dereceleri bakımından değişik oranlar sergilemektedir (Canözer ve Özahçı, 1992). Özellikle bölgenin en önemli yağlık zeytini olan Memecik çeşidinin çeliklerinin köklenme oranı, fidan üretimi yapılan diğer ticari zeytin çeşitlerden daha düşüktür. Zeytin çeliklerinin in vivo köklenmesinde, çeliklerin dikimini izleyen 3-7. günlerde kök uyarımı ile ilişkili içsel poliaminlerin (serbest, bağlı) miktarında önemli değişiklikler saptanmıştır (Rugini ve ark., 1991). Yaşlı dallardaki uyur meristemler uygun çevresel şartlar altında kök oluşturmasına rağmen, zeytinde önceden oluşmuş kök taslaklarının varlığı şimdiye kadar gösterilememiştir. Bu nedenle çelik üzerinde yeni kökler, sürgün ana bitkiden

*Sorumlu Yazar: zdalkilic@adu.edu.tr. Bu çalışma yüksek lisans tez ürünüdür.

Geliş Tarihi: 3 Şubat 2020

Kabul Tarihi: 10 Aralık 2020 
kesildikten sonra oluşacaktır. Bunlar yaralanma yolu ile uyarılan köklerdir. Dış çevre ile temas halinde olan çeliğin ölen dokularında geriye kalan dokular müsilaj oluşturarak daha içerideki dokuları korurlar. Aşırı su kaybı oluşacak iletim demetleri tiloz yapıştırıcı ile tıkanır. Sonuçta daha alt katmanlarda bulunan canlı hücreler bölünmeye başlar. İlk 12 hafta içinde özelleşmiş parankima hücreleri olan geniş kallus yumağı oluşturmaya başlar. Çeliğin tabanındaki kesik yüzeyin çevresinde şişkinlik ve kalınlaşmış kallus tabakası gözlenir (Fabbri ve ark., 2004). Domat ve Memecik çeşitlerinde floem içerisinde veya dışında küçük sklerenkima kümeleri belirlenmiş, daha önce meydana gelmiş kök taslaklarına rastlanmamıştır (Dolgun ve Tekintaş, 1998). Özkaya ve ark. (1998) ve Çelik ve Özkaya (1999) her 15 günde bir alınan örneklerde, çelikleri zor (Domat) ve kolay (Gemlik) köklenen zeytin çeşitlerinin çeliklerinde köklenmeyle ilişkili olarak anatomik yapılarında bir farklılık olmadığı belirlemiştir.

\section{Etilenin Kök Oluşumu Üzerine Etkisi}

Etilen $\left(\mathrm{C}_{2} \mathrm{H}_{4}\right)$ yan kök, kök tüyü ve adventif kök oluşumunu uyarmasında da etkilidir (Kaynak ve Ersoy, 1997; Algül ve ark., 2016). Etilen sentezinin uyarılması yoluyla oksinlerin faaliyete geçtiği düşünülmektedir (Fabbri ve ark., 2004). Etilenin adventif kök oluşumu ve kök gelişmesine etkisi olduğu bildirilmektedir. Çeliklere kıyasla kesilmemiş dallarda, odunlu bitkilere kıyasla otsu bitkilerde ve önceden oluşmuş kök taslaklarına sahip olan bitkilerde etilen yoluyla köklenme uyarımı daha başarılı olmaktadır (Hartmann ve ark., 1997). Mango (Mangifera indica) (Dhua ve ark. (1983), Avrupa ladini (Picea abies) (Bollmark ve Eliasson, 1990), kolay köklenen Gala ve zor köklenen Triple Red Delicious elma (Malus $\times$ domestica) çeşitlerinde (Harbage ve Stimart, 1996) ve fındıkta (Corylus sp.) (Gonzáles ve ark.'a atfen, (Yıldız ve Yılmaz, 2001) köklendirme çalışmalarında etilen kullanılmıştır.

\section{Zeytinin Çelik ile Köklendirilmesi ile İIgili Çalışmalar}

Zeytin çelikle çoğaltılabilen bir tür olmakla birlikte zeytin çeşitleri arasında köklenme yeteneği bakımından önemli farklılıklar söz konusudur (Hartmann ve ark., 1997). Türkiye'de yeşil çeliklerle yapılan çalışmada en yüksek köklenme oranı sisleme serasında \%29.0 ve alçak tünelde \%30.8 ile Leccio çeşidinde kaydedilmiştir. Ürdün'de yeşil çeliklerde en yüksek köklenme oranı sonbaharda \%52.3 ve ilkbaharda \%32.4 ile Manzanilla çeşidinden elde edilmiştir. Yeşil çeliklerin köklendirilmesinde Türkiye'deki çalışmada 6000 ppm IBA ve Ürdün'de 4000 ppm IBA kontrola göre daha etkili bulunmuştur (Shobolul ve Mendilcioğlu, 1985). İtalya'da Maurino ve Frangivento çeşidi zeytinlere kimyasal madde uygulamaları çelikler hazırlandıktan 0.0, 1.5, 3.0, 6.0 ve 12.0 saat sonra yapılmıştır. ACC uygulaması tek başına çelik köklenmesine etkili olmazken, IBA'in etkisini artırdığı bulunmuştur. ACC'nin etkisinin çeliğin kesiminden sonraki uygulama zamanına bağlı olduğu bulunmuştur. AVG tüm uygulama kombinasyonlarında köklenmeye olumsuz etki etmiştir. En yüksek köklenme oranı Maurino çeşidinde ACC+IBA 3 saat uygulamasından (\%37.5) elde edilmiştir (Bartolini ve ark., 1986). Antalya'da Tavşan Yüreği çeşidinden yıl boyunca her ay çelik hazırlanmıştır. Kış aylarında hazırlanan çelikler 6000 ppm IBA uygulamasına en iyi cevabı vermiştir. Kallus oluşturan çeliklere tekrar 3000 ppm IBA uygulaması çeliklerin köklenmesini önemli derecede artırmıştır (Baktır ve ark., 1991). En iyi köklenmeyi Kan Zeytini göstermiştir, bunu Memecik ve Tavşan Yüreği izlemiştir. Memecikte en iyi köklenme perlit ortamında 2000 ppm IBA (\%14) uygulamasından elde edilirken ticari preparat ve 4000 ppm IBA bunu izlemiştir (Ülger ve Baktır, 1992). Dikimden 60 gün sonra Gemlik'te \%19.4 köklenme gözlenirken Domat'ta köklenme olmamıştır. Dikimden 60 gün sonra şeker düzeyi Gemlik'te azalırken Domat'ta ise en yüksek değere ulaşmıştır. Nişasta her iki çeşitte de yüksek seyrederken Domat'ta her 3 örnek alma döneminde de daha yüksek bulunmuştur (Günver ve ark., 2000). Domat zeytin çeşidinin sisleme ortamına dikilen çeliklerine 5000 ppm IBA uygulamasından en yüksek köklenme oranı \%63.3 ile elde edilirken, 3000 ppm NAA uygulamasından \%36.6 köklenme elde edilmiştir. Tek başına salisilik asit uygulaması kök oluşturmamıştır. Salisilik asidin hem IBA hem de NAA uygulamasının 15 gün öncesinde ya da sonrasında uygulanması köklenmeyi önemli derecede engellemiştir (İsfendiyaroğlu ve Özeker, 2008). Alçak tünel sisleme ünitesinde Ayvalık Yağlık zeytin çeşidinin yarı odun çeliklerinin köklenmesi üzerine 4000 ppm IBA ve perlitvermikulit 1:1 ortamının zeytin çeliklerinin köklendirilmesinde üstün nitelikli bir ortam olduğu bildirilmiştir (İsfendiyaroğlu ve ark., 2009). Kalamata çeşidinde 2000 ppm IBA uygulamasında \%3'ten daha az köklenme olmuştur. Arbequina çeşidinde en yüksek köklenme \%76 ile yaz ayında alınan çeliklerden elde edilmiştir (Denaxa ve ark., 2012). Yabani 10 zeytin genotipinin 4000 ppm IBA ile köklenme oranı \%8.3 ile \%55.6 arasında değişmiştir. Çeliklerin yaprak taşıması (\%27.3) ya da taşımaması (\%25.9) istatistiki olarak önemli bulunmamıştır (Uğur ve ark., 2013). İran'da serada Manzanilla çeşidine uygulanan 3000 ppm IBA'nın kök sayısını, köklenme yüzdesini, kök uzunluğunu ve köklenme oranını arttırdığı tespit edilmiştir. Kök uzunluğu ve kök kuru ağırlığı gibi özelliklerde en yüksek etki 4000 ppm uygulamasında gözlenmiştir. İlkbaharda kesilen çelikler, değerlendirilen özellikleri içerisinde en yüksek etkiye sahip olduğunu göstermiştir (Khajehpour ve ark., 2014). Gemlik zeytin çeşidinin yarı odun çeliklerinin köklendirilmesi üzerine $1 \mathrm{ml} / \mathrm{L}$ Gabiokat'ın kontrole göre köklenme oranını 
önemli düzeyde artırdığını tespit edilmiştir. Sürgün sayısı (3.6 adet), ortalama sürgün uzunluğu (40.2 mm), kök sayısı (23.0 adet), ortalama kök uzunluğu (30.1 mm) ve köklenme düzeyi (3.7 mm) elde edilmiştir (Güler vd., 2017). Coratina zeytin çeşidinin odun çeliklerinde en yüksek köklenme oranı \%12.4 ve sürgün oluşumu \%35.5 ile 4000 ppm IBA'dan elde edilmiştir. Yarı odun çeliklerinde en yüksek köklenme oranı \%9.8 ve sürgün oluşumu \%30.1 ile 4000 ppm IBA'dan elde edilmiştir (Ameen ve ark., 2017). Coratina \%38.3, Frantoio \%32.6 ve Pendalino \%16.1 oranında köklenmiş; sürgün oluşturma oranı Coratina'da \%84.6, Frantoio'da \%81.3 ve Pendalino'da \%62.3 olarak kaydedilmiştir. Kök uzunluğu karşılaştırılmasında Frantoio'da 36.3 cm, Pendalino'da 15.6 $\mathrm{cm}$ ve Coratina'da $10.7 \mathrm{~cm}$ değerleri elde edilmiştir. 3000 ppm IBA uygulanan Coratina çeşidinin en iyi sonucu verdiği tespit edilmiştir (Jan ve ark., 2017). 300 ppm IBA kontrol, 1, 2,4 ve 8 saat bandırma şeklinde uygulanmada köklenme \%66.7 (Arbosana, 1 saat bandırma) ile \%0.0 (Arbequina 1 saat ve 8 saat bandırma) arasında değişmiştir (Inocente ve ark., 2018). Coursaky ve Frinto çeşitlerinin köklendirilmesi için 2000 ppm IBA'in yeterli olabileceği ancak daha zor köklenen Ashrasy ve Khdary çeşitlerin (yöresel) köklenmesi için 4000 ppm IBA tavsiye edilmiştir (Al-Hattab ve ark., 2018).

Bu çalışmanın amacı, Memecik zeytin çeşidinin yarı odun çeliklerinin köklenmesi üzerine etilenin etkisini araştırmaktır. Memecik çeşidinin çeliklerindeki köklenme oranının daha da artırılması, hem fidancılık sektörüne hem de ülke ekonomisine katkı sağlayabilecektir. Etilenin, Memecik zeytin çeliklerinin köklendirilmesinde ilk kez kullanılması bu tez çalışmasının özgün değerini oluşturmaktadır.

\section{MATERYAL VE YÖNTEM}

Çalışmada bitkisel materyal olarak Memecik zeytin çeşidi kullanılmıştır. Memecik, Ege Bölgesi'nin önemli bir yağlık ve sofralık çeşididir. Sinonimleri Taş Arası, Aşıyeli, Tekir, Gülümbe, Şehir ve Yağlık'tır. Büyük ve Küçük Menderes vadileri ile Muğla'da yaygın olan çeşit, Ege Bölgesi zeytin ağacı varlığının >\%50'ni ve Türkiye'deki toplam zeytin ağaç varlığının yaklaşık \%45.5'ini oluşturur (Shobolul ve Mendilcioğlu, 1985; Mendilcioğlu, 1999). Bu araştırmada kullanılan Memecik zeytin çeşidine ait çelikler, Nazilli'de bulunan özel bir zeytin üreticisinin bahçesindeki ağaçlardan, kış 2019 budama sezonunda elde edilmiştir. Sağlıklı, verimli ve tahminen 25-30 yaşında ağaçlardır.

Araştırmada oksin kaynağı olarak IBA $\left(\mathrm{C}_{12} \mathrm{H}_{13} \mathrm{NO}_{2}\right.$, Mol. Ağ.: $203.24 \mathrm{~g} / \mathrm{mol}$, Cat. No: 1.00354.0025, Merck, Kenilworth, $\mathrm{NJ}, \mathrm{USA})$ ve etilen kaynağı olarak $480 \mathrm{~g} / \mathrm{L}$ Ethephon $\left(\mathrm{Cl}-\mathrm{CH}_{2}-\right.$ $\mathrm{CH}_{2}-\mathrm{PO}_{3} \mathrm{H}_{2}$ ) içeren Efhun ${ }^{\circledR} \mathrm{SL}$ (Agrobest Grup Tar. İ. Toh. İml. İth. İhr. San. Tic.A.Ş, Kemalpaşa, İzmir) ticari preparat kullanılmıştır. Denemede IBA 0, 4000, 6000 ve 8000 ppm ile etilen 0, 50, 100 ve 150 ppm sıvı çözelti olarak kullanılmıştır.
Araştırma, Aydın ili Nazilli ilçesi Yeni Mahalle'de açık alana kurulan alçak tünel altındaki el yapımı sisleme ünitesinde plastik kasalar içerisine yerleştirilen tarımsal perlit ortamında gerçekleştirilmiştir. Yarı odun çelikleri bir yıllık sürgünlerin orta bölümlerinden $10-15 \mathrm{~cm}$ uzunluğunda, üzerlerinde 2-3 yaprak bulunan, dip kısımları düz, üst kısımları ise 45을 eğimle kesilerek hazırlanmıştır (Ferguson ve ark., 1994; Hartmann ve ark., 1997). Öncelikle 20 Şubat 2019'da çelikler 0, 50, 100 ve 150 ppm etilen içinde 1 gün bekletildikten sonra ertesi gün köklendirme ortamına dikilmiştir. 0 etilen+0 IBA uygulamasında çelikler 1 gün saf suda bekletildikten sonra dikim yapılmıştır. 0 etilen +4000 IBA, 0 etilen+6000 IBA ve 0 etilen+8000 IBA uygulamalarında çeliklerin 1-2 cm'lik dip bölümü solusyon içerisine 5 saniye bandırılıp kurutulduktan sonra dikim yapılmıştır. Farklı gün uygulamalarında ise köklendirme ortamlarından sökülen çeliklerin dip kısımları yıkanmış, fazla suyu süzülmüş ve dip kısımlarındaki kesik yeri 0.5-1.0 mm uzunlukta yapılan kesim ile tazelenmiştir. illk dikim tarihinde 50, 100 ve 150 ppm etilen uygulanan çeliklere, 10 gün (04 Mart 2019) ve 20 gün (14 Mart 2019) sonra 4000 ppm IBA uygulanmıştır. Çelikler alçak tünel sisleme ünitesinde köklendirilmiştir. Denemede 18 Mayıs 2019 tarihinden itibaren elektrikli battaniye ile alttan isıtma $\left(25^{\circ} \mathrm{C}\right)$ uygulanmıştır. Sisleme sistemi gün batımından, gün doğumuna kadar devre dışı bırakılmıştır. Sisleme ilk ay 15 dakikada 15-20 saniye, daha sonra 30 dakikada 15-20 saniye çalıştırılmıştır. Köklendirme ortamında 120 gün bırakılan çelikler, 18 Haziran 2019 tarihinde sökülmüştür. Uygulamaların çeliklerin köklenmesi üzerine olan etkilerini saptamak amacıyla, çeliklerde aşağıdaki köklenme özellikleri incelenmiştir:

Kallus oranı (\%): Çeliklerin dip bölümünün çevresinin $\left(360^{\circ}\right)$ kalluslanma durumu görsel değerlendirme (GD) ile 1: \%0, 2: \%25, 3: \%50, 4: \%75, 5: \%100 şeklinde sıralanmıştır. Köklenme oranı (\%) için her tekerrürdeki 10'ar çelikten köklenenler sayılmış ve yüzde olarak verilmiştir. Çelik başına kök sayısı (adet) her çelikte oluşan $1 \mathrm{~cm}$ 'den uzun kökler adet olarak sayılmış, kök uzunluğu $(\mathrm{cm})$ her çelikte oluşan 1 cm'den uzun köklerin uzunluğu cetvel ile ölçülmüştür. Kök çapı $(\mathrm{mm})$ için her çelikte oluşan $1 \mathrm{~cm}$ 'den uzun kökler dijital kumpas ile ölçülmüştür. Sürgün sayısı (adet), uzunluğu $(\mathrm{cm})$ ve çapı $(\mathrm{mm})$ için her çelikte oluşan $1 \mathrm{~cm}$ 'den uzun sürgünler kullanılmıştır. Deneme, üç tekerrürlü ve her tekerrürde 30 çelik yer alacak şekilde tesadüf parselleri deneme desenine göre yürütülmüştür. Deneme sonucu elde edilen verilerin değerlendirilmesinde tek yönlü varyans analizinde (ANOVA) TARIST istatistik paket programı kullanılmıştır. Incelenen özellikler arasındaki istatistiki farklılıklar, LSD çoklu karşılaştırma testi ile belirlenmiştir. 


\section{BULGULAR VE TARTIŞMA}

Memecik zeytini yarı odun çeliklerinin kallus (\%), köklenme oranı (\%), kök sayısı (adet/ çelik), kök uzunluğu (cm), kök çapı $(\mathrm{mm})$, sürgün uzunluğu $(\mathrm{cm})$, sürgün çapı $(\mathrm{mm})$ ve sürgün sayısı (adet) ölçümlerinden elde edilen bulgular aşağıda verilmiştir. Uygulamalar (ppm): 1: 0 etilen+0 IBA, 2: 4000 etilen+0 IBA, 3: 6000 etilen+0 IBA, 4: 8000 etilen+0 IBA, 5: 50 etilen+4000 IBA (10.gün), 6: 100 etilen+4000 IBA (10.gün), 7: 150 etilen+4000 IBA (10.gün), 8: 50 etilen+4000 IBA (20.gün), 9: 100 etilen+4000 IBA (20.gün), 10: 150 etilen+4000 IBA (20.gün) (Şekil 1).

Kallus Oranı (\%): Kallus oranı en düşük 0 etilen+0 IBA (\%16.8) ile en yüksek 150 etilen+4000 IBA (20.gün) (\%44.7) dozları arasında değişmiştir (Şekil 1a). 0 etilen+8000 IBA $\% 44.0,100$ etilen+4000 IBA (20.gün) \%42.5, 50 etilen+4000 IBA (10.gün) \%40.0, 150 etilen+4000 IBA (10.gün) \%38.4, 50 etilen+4000 IBA (20.gün) \% 37.6, 0 etilen+6000 IBA \%37.0, 0 etilen+4000 IBA \%32.4, 100 etilen+4000 IBA (10.gün) \%25.8 kallus oranı elde edilmiştir. Çelik ve Özkaya (1999), zor ve kolay köklenen zeytin çeşitlerinin çeliklerinin köklenmeyle ilişkili olarak anatomik yapılarında bir farkılık olmadığını, mevcut metabolik aktivitenin kök yerine yoğun kallus oluşumunda kullanıldığını bildirmişlerdir.

Köklenme Oranı (\%): En düşük 0 etilen+0 IBA (\%2.2) ve 150 etilen+4000 IBA (10.gün) (\%2.2) ile en yüksek 0 etilen+6000 IBA dozunda (\%44.4) dozları arasında belirlenmiştir (Şekil 1b). 0 etilen+8000 IBA \%42.2, 0 etilen+4000 IBA \%16.7, 50 etilen+4000 IBA (10.gün) \%11.1, 50 etilen+4000 IBA (20.gün) \%11.1, 100 etilen + 4000 IBA (20.gün) \%10.0, 150 etilen+4000 IBA (20.gün) \%8.9, 100 etilen+4000 IBA (10.gün) \%5.6 köklenme oranı elde edilmiştir. Okduman (2013), Domat zeytin çeşidinde farklı günlerde yapılan hormon uygulamalarında, hormon×gün interaksiyonu her ne kadar köklenme oranı üzerinde istatistiki açıdan önemsiz etkide bulunsa da, 0 . günde (dikim günü) $2 \mathrm{~g} / \mathrm{L}^{\prime} l i k$ NAA uygulanmış çelikler, $\% 83.3$ ile en yüksek oranda köklenirken, en düşük köklenme $\% 53.3$ ile 15 . günde yapılan IBA ve NAA uygulamalarında görülmüştür. Çeliğin kök kalitesini belirleyen özellikler (köklenme oranı, kök adedi ve kök uzunluğu) açısından, en yüksek değerler 0 . gün yapılan $2 \mathrm{~g} / \mathrm{L}^{\prime}$ lik NAA ile elde edilmiştir.

Kök Sayısı (adet): En en düşük 150 etilen+4000 IBA (10.gün) dozunda 1.0 adet ile en yüksek 0 etilen+6000 IBA dozunda 13.3 adet arasında değişmiştir (Şekil $1 \mathrm{c}$ ). Kök sayısı 0 etilen+8000 IBA'da 12.7 adet, 0 etilen+4000 IBA'da 5.0 adet, 50 etilen+4000 IBA (10.gün)'da 3.3 adet, 50 etilen+4000 IBA (20.gün)'da 3.3 adet, 100 etilen+4000 IBA (20.gün)'da 3.0 adet, 150 etilen+4000 IBA (20.gün)'da 2.7 adet, 100 etilen+4000 IBA (10.gün)'da 2.5 adet ve 0 etilen+0 IBA (kontrol)'da 2.0 adet olarak belirlenmiştir. Al-Absi (2003), Nabali çeşidinin daha kolay köklendiğini, daha 168 yüksek köklenme yüzdesi ve kök sayısına sahip olduğunu, en uygun çelik alma zamanının aralık ayı olduğunu, 6000 ppm IBA'nın en yüksek köklenme yüzdesini verdiğini bildirmiştir. Ameen Al-Imam (2011), Manzanillo'da en yüksek köklenme yüzdesi ve kök sayısı, 3000 ppm'lik IBA ile muamele edilmiş çeliklerden elde edilmiştir.

Kök Uzunluğu $(\mathrm{cm})$ : Kök uzunluğu 1.0-7.0 cm arasında değişmiştir (Şekil 1d). Kök uzunluğu 50 etilen+4000 IBA (10.gün)'da $7.0 \mathrm{~cm}, 100$ etilen+4000 IBA (10.gün)'da $6.4 \mathrm{~cm}$, 0 etilen+6000 IBA' da $5.1 \mathrm{~cm}$, 0 etilen+8000 IBA'da $5.0 \mathrm{~cm}$, 150 etilen+4000 IBA (20.gün)'da $5.0 \mathrm{~cm}, 0$ etilen+4000 IBA'da $4.8 \mathrm{~cm}, 50$ etilen+4000 IBA (20.gün)'da $4.6 \mathrm{~cm}, 0$ etilen+0 IBA (kontrol)'da $4.0 \mathrm{~cm}, 100$ etilen+4000 IBA (20.gün)'da $2.1 \mathrm{~cm}$ ve 150 etilen+4000 IBA (10.gün)'da 1.0 $\mathrm{cm}^{\prime}$ dir. Çeşitlerin kök uzunluklarının farklııı göstermesi çeşidin genetik yapısının farklı olması yanı sıra köklenme ortamı ve koşullarının (nem ve sıcaklık) değişken olmasından kaynaklanmaktadır. Ayanoğlu ve ark. (2000) ve İsfendiyaroğlu ve ark. (2009) farklı köklendirme ortamların kök uzunluğu üzerine etkilerinin farklılık gösterdiğini saptamışlardır.

Kök Çapı (mm): Kök çapı 1.0-3.0 mm arasında değişmiştir (Şekil 1e). Kök çapı 150 etilen+4000 IBA (10.gün)'da 3.0 $\mathrm{mm}, 0$ etilen +4000 IBA' da $1.8 \mathrm{~mm}$, 0 etilen +6000 IBA' da 1.7 $\mathrm{mm}, 0$ etilen +8000 IBA'da $1.6 \mathrm{~mm}, 100$ etilen +4000 IBA (10.gün)'da $1.5 \mathrm{~mm}, 50$ etilen+4000 IBA (10.gün)'da 1.4 $\mathrm{mm}, 150$ etilen+4000 IBA (20.gün)'da $1.4 \mathrm{~mm}, 50$ etilen+4000 IBA (20.gün)'da $1.3 \mathrm{~mm}, 0$ etilen+0 IBA (kontrol)'da $1.2 \mathrm{~mm}$ ve 100 etilen+4000 IBA (20.gün)'da 1.0 mm'dir.

Sürgün Sayısı (adet): Sürgün sayısının istatistiksel olarak önemsiz olduğu tespit edilmiştir. Sürgün sayısı 0.0-3.3 adet arasında değişmiştir (Şekil 1f). Farklı dozlar arasında sürgün sayısı 100 etilen+4000 IBA (10.gün)'da 3.3 adet, 0 etilen+6000 IBA'da 1.9 adet, 100 etilen+4000 IBA (20.gün) 1.8 adet, 0 etilen+8000 IBA 1.8 adet, 50 etilen+4000 IBA (20.gün) 1.8 adet, 150 etilen+4000 IBA (20.gün) 1.6 adet, 50 etilen+4000 IBA (10.gün) 1.4 adet, 0 etilen+4000 IBA'da 1.4 adettir. 0 etilen+0 IBA (kontrol) ve 150 etilen+4000 IBA (10.gün)'da sürgün elde edilememiştir. Uğur ve ark. (2013), yabani zeytin genotiplerinin çeliklerinin köklendirilmesinde 4000 ppm IBA kullanılmıştır. Çeliklerdeki ortalama sürgün sayısı 1.3 adet (1. 2 ve 3 nolu genotipler) ile 3.3 ( 9 nolu genotip) adet arasında değişmiştir. $T$. harzianum'un zeytin çeliklerine uygulanmasında, köklenme sonrasında uygulamanın yapılması ve granül formda, doğrudan köklerine temas ettirilmesi, kök sayısının ve kök uzunluğunun artmasında daha etkili olduğu görülmüştür (Taşşı, 2010). Tüm uygulamalarda $T$. harzianum'un fidan çapına, sürgün sayısına ve bitki uzunluğuna etkilerinin istatistiki olarak önemsiz olduğu bildirilmiştir. 

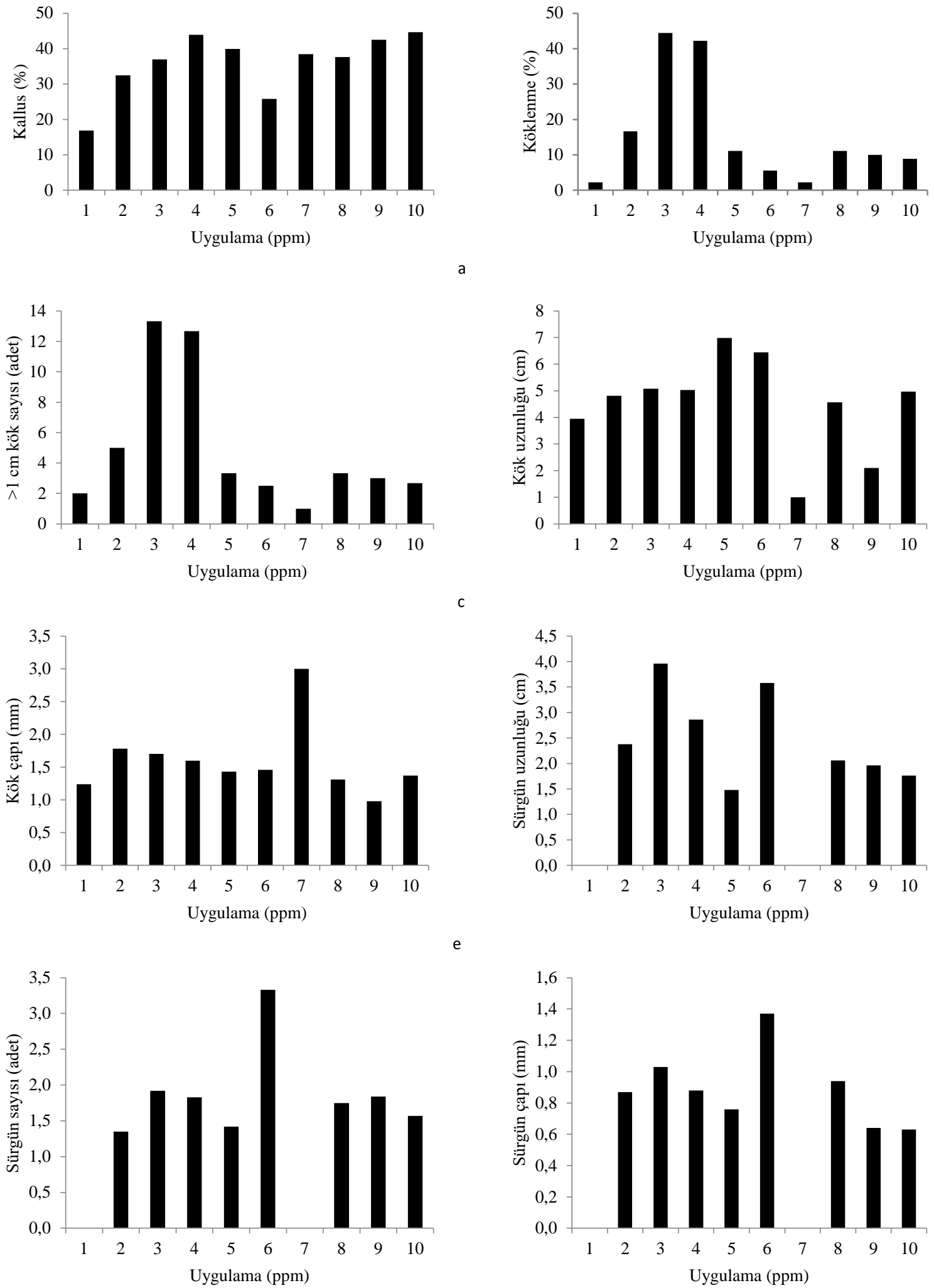

g

Şekil 1. Memecik zeytini yarı odun çeliklerindeki a) kallus oranı (\%), b) köklenme oranı (\%), c) kök sayısı (adet), d) kök uzunluğu (cm), e) kök çapı (mm), f) sürgün sayısı (adet), g) sürgün uzunluğu $(\mathrm{cm}), \mathrm{h})$ sürgün çapı $(\mathrm{mm})$ 
Tüm uygulamalarda $T$. harzianum'un fidan çapına, sürgün sayısına ve bitki uzunluğuna etkilerinin istatistiki olarak önemsiz olduğunu bildirmiştir. Awan ve ark. (2001) 3000 ppm IBA ile 5 dakika muamele edilen Azerbaijan ve Earleeg zeytin çeşitlerinin çelik başına yaprak sayısı (65.9 ve 64.6) ve sürgün uzunluğunu $(18.2 \mathrm{~cm}$ ve $17.9 \mathrm{~cm})$ gösterdiğini belirtmişlerdir. Azerbaijan çeşidinin önemli derecede daha yüksek sürme yüzdesine (\%48.7) ve çelik basına sürgün sayısına (4.9 adet) sahip olduğunu tespit etmişlerdir.

Sürgün Uzunluğu $(\mathbf{c m})$ : Sürgün uzunluğunun istatistiksel olarak önemsiz olduğu belirlenmiştir. Sürgün uzunluğu en düşük 50 etilen+4000 IBA (10.gün) dozunda $1.5 \mathrm{~cm}$ ile en yüksek 0 etilen+6000 IBA dozunda $4.0 \mathrm{~cm}$ arasında değişmiştir (Şekil 1g). 100 etilen+4000 IBA (10.gün) $3.6 \mathrm{~cm}$, 0 etilen+8000 IBA $2.9 \mathrm{~cm}, 0$ etilen+4000 IBA $2.4 \mathrm{~cm}, 50$ etilen+4000 IBA (20.gün) $2.1 \mathrm{~cm}, 100$ etilen+4000 IBA (20.gün) $2.0 \mathrm{~cm}, 150$ etilen+4000 IBA (20.gün) $1.8 \mathrm{~cm}$ 'dir. 0 etilen+0 IBA (kontrol) ve 150 etilen+4000 IBA (10.gün)'da sürgün elde edilememiştir. Zor köklenen Domat ve Sarı Ulak zeytin çeşidi ile kolay köklenen Gemlik zeytin çeşitlerinin çeliklerine farklı oksin konsantrasyonları (IBA ve IAA) ile beraber Agrobacterium rhizogenes bakterisinin saçak kök oluşturma yeteneğini kullanarak, çeliklerin köklenme başarıları incelenmiştir. Sürgün uzunluğu bakımından uygulama, çeşit ve uygulama çeşit interaksiyonu arasında istatistiksel bir fark saptanmamıştır (Tütüncü ve ark., 2016).

Sürgün Çapı (mm): Memecik zeytini yarı odun çeliklerinin sürgün çaplarının istatistiksel olarak önemsiz olduğu gözlemlenmiştir. Sürgün çapı 0.0-1.4 mm arasında değişmiştir (Şekil 1h). Farklı dozlar arasında sürgün çapı 100 etilen+4000 IBA (10.gün)'da $1.4 \mathrm{~mm}, 0$ etilen+6000 IBA'da $1.0 \mathrm{~mm}, 50$ etilen+4000 IBA (20.gün) $1.0 \mathrm{~mm}, 0$ etilen+8000 IBA $0.9 \mathrm{~mm}, 0$ etilen+4000 IBA $0.9 \mathrm{~mm}, 50$ etilen+4000 IBA (10.gün) $0.8 \mathrm{~mm}, 100$ etilen+4000 IBA (20.gün) $0.6 \mathrm{~mm}, 150$ etilen+4000 (20.gün) 0.6 mm'dir. 0 etilen+0 IBA (kontrol) ve 150 etilen+4000 IBA (10.gün)'da sürgün elde edilememiştir.

\section{SONUÇ}

Yapılan bu çalışmadaki amaç köklendirme olduğundan dolayı Memecik zeytin çeşidinin yarı odun çeliklerinde en ekonomik uygulama olarak 0 etilen+6000 IBA dozu (\%44.4) önerilmektedir. Çelik ile ticari fidan çoğaltımda kabul edilebilir köklenme oranı \%75 ve şaşırtmadan/aktarmadan sonraki fidan randımanı \%60-65 olarak belirtilmektedir (M. İsfendiyaroğlu, kişisel görüşme). Artan etilen dozları Memecik yarı odun çeliklerinin köklenmesini azalttığı için, 50 ppm'den daha düşük etilen dozlarının denemesi gerekmektedir. Bundan sonra zeytin çelik köklendirmesi konusunda yapılacak çalışmalarda etilenden sonra kullanılan IBA dozunun 4000 ppm değil de 5000-8000 ppm doz aralıklarında denenmesi tavsiye edilir. IBA uygulaması zamanının ve dozunun etilen uygulamasından kaç gün sonra yapılacağı hakkında çalışmaların yapılması yararlı olabilecektir. Kök taslaklarının oluşmasında tek başına etileninin ve diğer bitki büyüme düzenleyicilerinin, organik preparatların ve kimyasal maddelerin etkili olup olmayacağı ve en uygun uygulama zamanın araştırılması fayda sağlayabilecektir. Kullanılacak çelik tiplerinin (yaşlı dal, bir yaşlı dal, yarı odun çeliği ya da yeşil çelik vb.) detaylı şekilde araştırılması daha iyi köklenme elde edilmesinde denebilir. Odun çelikleri zor köklenen Memecik çeşidinin doku kültürü yöntemleri ile çoğaltılması çalışmalarının yapılması önerilmektedir. Dikimden önce çeliklere katlama uygulaması yapılması nem içeriğinin korunmasına yardımcı olabilecektir.

\section{TEŞEKKÜR}

Yazarlar, denemede kullanılan Memecik zeytin çeliklerinin ücretsiz temin edilmesine yardımcı olan Sayın Dursun ARSLAN'a teşekkür eder. Bu makale, araştırmanın planlaması aşamasındaki yardımından dolayı rahmetli Prof. Dr. F. Ekmel TEKINTAŞ'a atfedilmiştir.

\section{KAYNAKLAR}

Al-Absi KM (2003) Rooting Response of 'Nabali' and 'Improved Nabali' Olive Cuttings to Indole Butyric Acid Concentration and Collection Season. PakistanJournal of Biological Sciences, 6(24): 20402043.

Algül BE, Tekintaş FE, Günver Dalkılıç, G (2016) Bitki Büyüme Düzenleyicilerinin Kullanımı ve İçsel Hormonların Biyosentezini Arttırıcı Uygulamalar. ADÜ Ziraat Fakültesi Dergisi, 13(2):87-95.

Al-Hattab ZN, Abdulmajeed WA, Al-Ni MA (2018) The Influence of Growth Regulators on the Rooting Capacity of Semi Hardwood Cuttings of Olive Olea europaea L. Bioscience Research, 15(1): 412-417.

Ameen Al-Imam NM (2011) Effect of Some Factors on Rooting Percentage and Subsequent Growth of Manzanillo Olive Cuttings (Olea europaea L.). Mesopotamia Journal of Agriculture, 39(2):9-18.

Ameen, A., Ahmad, J., Raza, S. 2017. Effect of IBA Concentration on the Production of Coratina Olive Plant. International Journal of Advances in Scientific Research, 3(11): 125-128.

Anonim (2018) Ulusal Zeytin ve Zeytinyağı Konseyi. http://uzzk.org/Belgeler/TURKIYE_REKOLTE_RAPOR_ 2017_2018.pdf. Erişim Tarihi: 30/07/2019.

Anonim (2019) FAOSTAT. Food and Agricultural Organisation.

http://www.fao.org/faostat/en/\#data/QC. Erişim Tarihi: 30/07/2019.

Awan AA, Iqbal J, Wahab F (2001) Performance of Olive (Olea europaea L.) Cuttings Taken from Different Varieties in the Agro-climatic Conditions of Peshawar. Journal of Biological Sciences, 1(6): 440-441.

Ayanoğlu H, Toplu C, Bayazit S, Yılmaz S (2000) Değişik Köklendirme Ortamlarının Bazı Zeytin Çeliklerinin Köklendirilmeleri Üzerine Etkisi. 1. Zeytincilik Sempozyumu, 6-9 Haziran 2000, Bursa, 387-393.

Baktır I, Ülger S, Tiga S (1991) Determination of Rooting of Hardwood Cuttings of Tavsan Yuregi Olive Cultivar Treated with Different IBA Concentrations. Olea, 21:3.

Bartolini G, Tattini M, Fabbri A (1986) The Effects of Regulators of Ethylene Synthesis on Rooting of Olea europaea L. Cuttings. Acta Horticulturae, 179:841846. 
Bollmark M, Eliasson L (1990) Ethylene Accelerates the Breakdown of Cytokinins and Thereby Stimulates Rooting in Norway spruce Hypocotyl Cuttings. Physiologia Plantarum, 80: 534-540.

Canözer Ö, Özahçı E (1992) Zeytin Çeliklerinin Belli Hormon Konsantrasyonlarında Köklenme Nispetlerinin Tesbiti. Türkiye I. Ulusal Bahçe Bitkileri Kongresi, 13-16 Ekim 1992, Bornova-İzmir, 165-169.

Çelik M, Özkaya MT (1999) Kolay ve Zor Köklenen Zeytin Çeliklerinde Köklenme Süresince Anatomik Yapıdaki Değişimin Belirlenmesi. Türkiye III. Ulusal Bahçe Bitkileri Kongresi, 14-17 Eylül 1999, Ankara, 663-666.

Denaxa N-K, Vemmos SN, Roussos PA (2012) The Role of Endogenous Carbohydrates and Seasonal Variation in Rooting Ability of Cuttings of an Easy and a Hard to Root Olive Cultivars (Olea europaea L.). Scientia Horticulturae, 143: 19-28.

Dhua RS, Mitra SK, Sen SK, Bose TK (1983) Changes in Endogenous Growth Substances Cofactors and Metabolites in the Rooting of Mango Cutting. Acta Horticulturae, 134: 147-161.

Dolgun O, Tekintaş FE (1998) Zeytinin Aşı ve Çelikle Çoğaltılması Üzerine Anatomik ve Histolojik Incelemeler. Ege Bölgesi 1. Tarım Kongresi, 7-11 Eylül 1998, Aydın, 48-55.

Fabbri A, Bartolini G, Lambardi M, Kailis GS (2004) Olive Propagation Manual. CSIRO, Landlinks Press, Collingwood, Australia.

Ferguson L, Sibbett GS, Martin GC (1994) Olive Production Manual. University of California, Division of Agriculture and Natural Resources Publication 3353, Oakland, CA, USA.

Güler Z, Özkaya MY, Dousti S (2017) Gemlik Zeytin Çeşidinin Yarı Odun Çeliklerinin Köklendirilmesi. Zeytin Bilimi, 7 (1): 1-4.

Günver G, Seferoğlu S, Seferoğlu G, Dolgun O, Tekintaş FE (2000). Gemlik ve Domat Zeytin Çeşitlerinde Çelik Köklenmesi ile Bazı Biyokimyasal Özellikler Arasında İlişkiler. Türkiye 1. Zeytincilik Sempozyumu, 6-9 Haziran 2000, Bursa, 133-139.

Harbage JF, Stimart DP (1996) Ethylene Does Not Promote Adventitious Root Initiation on Apple Microcuttings. Journal of the American Society for Horticultural Science, 121(5):880-885.

Hartmann HT, Kester DE, Davies F, Geneve YR (1997) Plant Propagation: Principles and Practices. $6^{\text {th }}$ ed. PrenticeHall, Inc., Upper Saddle River, New Jersey, NJ, USA.

Inocente VHH, Nienow AA, Tre L (2018) Time of Treatment with IBA in Olive Cultivars Rooting. Revista Brasileira de Fruticultura, 40(1): e-800.

İsfendiyaroğlu M, Özeker, E (2008) Rooting of Olea europaea 'Domat' Cuttings by Auxin and Salicylic Acid Treatments. Pakistan Journal of Botany, 40(3): 11351141.
KARALTI M, DALKILIÇ Z

İsfendiyaroğlu M, Özeker E, Başer S (2009) Rooting of 'Ayvalık' Olive Cuttings in Different Media. Spanish Journal of Agricultural Research, 7(1): 165-172.

Jan S, Ilyas M, Samar IK, Ali N, Anjum MM, Ullah A, Zahir RU, Shuaeb MN (2017) Response of Rooting of Various Olive Cultivars to IBA (Indol Butaric Acid). Agricultural Research and Technology, 9(2): 1-5.

Kaynak L, Ersoy N (1997) Bitki Büyüme Düzenleyicilerinin Genel Özellikleri ve Kullanım Alanları. Akdeniz Üniversitesi Ziraat Fakültesi Dergisi, 10: 223-236.

Khajehpour G, Jamíeizadeh V, Khajehpour N (2014) Effect of Different Concentrations of IBA (Indulebutyric Acid) Hormone and Cutting Season on the Rooting of the Cuttings of Olive (Olea europaea L.) Manzanilla. International Journal of Advanced Biological and Biomedical Research, 2(12): 2920-2924.

Mendilcioğlu K (1999) Subtropik Iklim Meyveleri: Zeytin. Ege Üniv. Ziraat Fak. Yayınları Ders Notları: 12/6. Bornova-İzmir.

Okduman M (2013) Değişik Oksin Uygulamalarının 'Domat' Zeytini (Olea europaea L.) Çeliklerinin Köklenmesi Üzerine Etkileri. Yüksek Lisans Tezi. Ege Üniversitesi Fen Bilimleri Enstitüsü, İzmir.

Özkaya MT, Çelik M, Algan G (1998) Anatomy of Adventitious Root Formation in Stem Cuttings of the Easy-to-Root (Gemlik) and Hard-to-Root (Domat) Olive Cultivars. Proceedings of the First Balkan Botanical Congress, In: Tsekos I, Moustakas M, (eds.), Springer Netherlands, 435-438.

Rugini E, Luppino M, de Agazino M (1991) Endogenous Polyamine and Root Morphogenesis Variations under Different Treatments in In Vitro Explant of Olive. Acta Horticulturae, 300: 225-232.

Shobolul A, Mendilcioğlu K (1985) Zeytinin Tohumla ve Yeşil Çeliklerle Üretilmesi Üzerinde Araştırmalar. Ege Üniversitesi Ziraat Fakültesi Dergisi, 22(1): 49-60.

Taşçı S, Gündoğdu MA, Gür E, Şeker M (2010) Gemlik Zeytin Çeşidi (Olea europaea L.) Çeliklerinde Trichoderma harzianum Uygulamalarının Kök Gelişimi, Fidan Kalitesi ve Karbonhidrat Birikimi Üzerine Etkilerinin Belirlenmesi. Zeytin Bilimi, 1(2): 49-55.

Tütüncü $M$, Çömlekçioğlu $S$, Şimşek Ö, İzgü $T$, Küden $A B$ (2016) Bazı Zeytin Çeşitlerinin Çeliklerinin Köklenme Olanaklarının Araştırılması. BAHÇE, 45(Özel Sayı): 379383.

Uğur R, Altun Ö, Kodaz HM (2013) Bazı Yabani Zeytin Genotiplerinin (Olea europaea var. oleaster) Çelikle Köklenebilme Olanaklarının Araştırılması. Alatarım, 12(2): 25-28.

Ülger S, Baktır i 1(992) Üç Değişik Köklendirme Ortamında, IBA Uygulanmış Zeytin Çeliklerinin Köklendirilmesi. Türkiye I. Ulusal Bahçe Bitkileri Kongresi, 13-16 Ekim 1992, Bornova, İzmir, 1: 179-182.

Yıldız K, Yılmaz H (2001) Adventif Kök Oluşumu Üzerine Etilenin Etkisi. Derim, 18(1): 39-45. 
